Original Research Article

\title{
Evaluation of antidiabetic efficacy of Murraya koenigii on Streptozotocin induced diabetes in experimental rats
}

\author{
Rajesh Kumar Suman ${ }^{1 *}$, Ipseeta Ray Mohanty ${ }^{2}$, Manjusha K. Borde ${ }^{3}$, Y. A. Deshmukh², \\ Anurag Pathak ${ }^{1}$, Arun Kumar Adhikari ${ }^{1}$, H. K. Singh ${ }^{1}$
}

\begin{abstract}
${ }^{1}$ Department of Pharmacology, Hind Institute of Medical Sciences, Mau, Lucknow, India ${ }^{2}$ Department of Pharmacology, MGM Medical College, Navi Mumbai, Maharashtra, India ${ }^{3}$ Department of Pharmacology, Sinhgad Dental College, Pune, Maharashtra, India
\end{abstract}

Received: 13 June 2019

Revised: 29 June 2019

Accepted: 06 July 2019

*Correspondence to:

Dr. Rajesh Kumar Suman, Email: rajeshsuman2043@ gmail.com

Copyright: (C) the author(s), publisher and licensee Medip Academy. This is an openaccess article distributed under the terms of the Creative Commons Attribution NonCommercial License, which permits unrestricted noncommercial use, distribution, and reproduction in any medium, provided the original work is properly cited.

\begin{abstract}
Background: The medicinal plant Murraya koenigii shown to have a wide variety of pharmacological activities (hypoglycemic and hypolipidemic). Objective of this study is the present study was designed to evaluate Antidiabetic and Hypolipidemic property of Murraya koenigii in experimentally induced diabetes in rats.

Methods: Experimental diabetes was produced with single dose of Streptozotocin (STZ): $45 \mathrm{mg} / \mathrm{kg}$ IP. The rats were randomly allocated in various groups for 37 days. After the confirmation of diabetes on $7^{\text {th }}$ day $(>200 \mathrm{mg} / \mathrm{dl})$, hydroalcoholic extract of Murraya koenigii $(500 \mathrm{mg} / \mathrm{kg}$ ) was administered orally to experimental rats from day $7^{\text {th }}$ day and continued for 37 days thereafter. Various antidiabetic (Glucose, HbA1C), metabolic (Lipid profile), safety (pancreatic lipase, Creatinine, SGPT, Histopathology of Liver and Kidney) were evaluated in various group.

Results: Efficacy of Murraya koenigii was observed on various parameter of diabetes. Administration of STZ resulted in a significant decrease in diabetic changes (increase in blood glucose, HbA1C), altered lipid profile $(\mathrm{p}<0.01)$ in the Control group rats as compared to sham group. Murraya koenigii treatment demonstrated significant antidiabetic indicated by restoration of blood glucose, HbA1C level ( $\mathrm{p}<0.01$ ) compared to Control group. In addition, Murraya koenigii also documented hypolipidemic property of test drug. As per biochemical assessment of Pancreatic lipase, Serum creatinine, SGPT and Histopathological report, the test drug reduce the pancreatic, liver and renal marker and also showed safe to pancreas, Liver and kidney. The histopathological assessment of the liver and kidney confirmed the biochemical findings.
\end{abstract}

Conclusions: The study concluded that the Murraya koenigii possess antidiabetic efficacy

Keywords: Blood glucose, Diabetes, Experimental rats, Medicinal plant, Murraya koenigii, Streptozotocin

\section{INTRODUCTION}

Many herbal agents have been described for the treatment of diabetic mellitus in ancient literature. ${ }^{1,2}$ The global prevalence of type 2 diabetes mellitus (T2DM) is on the rise and at the current rate the estimates for the year 2000 through 2030 show that this global epidemic will have an increase from 171-366 million patients. ${ }^{3}$
Curry leaf extract possess the property to decrease blood cholesterol and blood glucose level in diabetic ob/ob mice. Mice were given daily injection of $80 \mathrm{mg} / \mathrm{kg}$ of leaves extract intraperitonially for 10 consecutive days. Blood glucose was found to be reduced after the administration of extract. This study suggests that Murraya koenigii may be proved to be clinically important in improving the management of type 2 diabetes. ${ }^{4,5}$ 
Diet has been recognized as corner stone in the management of diabetes mellitus. Spices are common dietary adjuncts that contribute to be the taste and flavor of foods. Besides spices it is also known to exert several beneficial physicochemical effects6. Curry leaf tree (Murraya koenigii L., Family: Rutaceae) is a plant which has various important uses in the traditional system of medicine in Eastern Asia. Based on ethnomedicine, Murraya koenigii is used as a stimulant, antidysentric and for the management of diabetes Mellitus. The plant is highly valued for its leaves an important ingredient in an Indian cuisine to promote appetite and digestion. ${ }^{4}$

A single oral administration of variable dose level (200, 300 and $400 \mathrm{mg}$ ) aqueous extract leads to lowering of blood glucose level in normal as well as alloxan induced diabetes rabbit's conclusion from this study suggested that aqueous extracts of these levels may be prescribed as adjunct to dietary treatment for controlling diabetes mellitus. The effect of daily oral administration of aqueous extract $(600 \mathrm{mg} / \mathrm{kg}$ body weight $)$ and methanolic extract (200 mg/kg body weight) of Murraya koenigii leaves for a period of eight weeks on blood glucose and plasma insulin level was studied in alloxan induced diabetic rat. Study suggested that the hypoglycemic effect may be mediated through stimulating insulin synthesis and/or secretion from the beta cells of pancreatic islets of Langerhans. ${ }^{7,8}$

On various studies suggest that, the leaf extract of Murraya koenigii (Curry leaf) possess antidiabetic potential. Thus, the present study designed to assess the hydroalcoholic extract of Murraya koenigii on experimentally induced diabetes in rats. Objective of this study is to evaluate the antidiabetic properties of hydroalcoholic extract of Murraya koenigii.

\section{METHODS}

\section{Plant extract}

The hydroalcoholic extract of Murraya koenigii was extracted by using curry leaf powder in Soxhlet Apparatus.

\section{Preparation of extract}

The leaf of Murraya koenigii were collected from local market. The extraction procedure was carried out in a Soxhlet apparatus with $100 \mathrm{gm}$ of coarse powder of the leaf of Murraya koenigii using hydro alcohol $(500 \mathrm{ml})$ for $24 \mathrm{hrs}$ and filtered. The concentrated extract was then evaporated in a vacuum oven at $40^{\circ} \mathrm{C}$ to achieve dryness. The dried extract was stored at $4^{\circ} \mathrm{C}$ in air-free sterile container in a refrigerator for further experiment.

\section{Chemicals}

Streptozotocin was purchased from Sigma Aldrich, United State of America. All other chemicals and reagents used were of analytical grade.

\section{Preparation of dose}

There various dose 200 to $600 \mathrm{mg} / \mathrm{kg}$ body weight was used in previous studies. We have selected $500 \mathrm{mg} / \mathrm{kg}$ body weight and was dissolved in distilled water and fed orally.

\section{Experimental animal}

White male albino rats 150-200 gm were purchased from the Bombay Veterinary College, Parel, Mumbai. Animals were maintained under laboratory conditions [temperature $\left(20 \pm 2^{\circ} \mathrm{C}\right)$ and photoperiod (12 hr light and $12 \mathrm{hr}$ dark cycle)]. Animals were allowed ad libitum to food and tap water. Rats were allowed to acclimatize for one week before the onset of the experiment.

\section{Induction of diabetes}

Diabetes was induced by using Streptozotocin as diabetogenic agent. Streptozotocin ( $45 \mathrm{mg} / \mathrm{kg}$ body weight) was dissolved in ice cold citrate buffer ( $\mathrm{pH} 4.5$ ) immediately before use. The solution was injected intraperitonially in the dose of $45 \mathrm{mg} / \mathrm{kg}$ body weight in rats. $5 \%$ glucose solution was administered orally for 24 hrs to prevent mortality due to initial hypoglycemia induced by Streptozotocin. After $72 \mathrm{hrs}$ of Streptozotocin injection, blood glucose levels were tested using commercially available kit Glucometer. The rats with blood glucose level above $200 \mathrm{mg} / \mathrm{dl}$ on $7^{\text {th }}$ day were considered to be diabetic and were used in the experiment.

\section{Experimental design}

The animals will be assigned to the following experimental groups.

Group 1: Sham group (Healthy Control): Rats were administered $0.9 \%$ normal saline per orally using a feeding cannula for 37 days and then sacrificed. There were 8 animals in this group.

Group 2: Control Group (Diabetes Control): The rats were administered $45 \mathrm{mg} / \mathrm{kg}$ Streptozotocin on day 0 to induce diabetes. The rats were maintained for 37 days. There were 8 animals in this group.

Group 3: Test group (Treated with Murraya koenigii Group). The rats were administered $45 \mathrm{mg} / \mathrm{kg}$ Streptozotocin on day 0 to induce diabetes. The hydroalcoholic extract of Murraya koenigii were fed orally for 30 days from 7 th day to $37^{\text {th }}$ day in dose $500 \mathrm{mg} / \mathrm{kg}$. There were 8 animals in this group.

\section{Experimental procedure}

All animals were allowed free access normal pellet diet for period study. The Streptozotocin $45 \mathrm{mg} / \mathrm{kg}$ were administered to Diabetic Control group rat to produce diabetes. After the Streptozotocin, the Blood glucose by 
using glucometer from rat tail vein on $2^{\text {nd }}, 3^{\text {rd }}$ and $7^{\text {th }}$ were checked to confirm diabetes. The blood glucose more than $200 \mathrm{mg} / \mathrm{dl}$ on $7^{\text {th }}$ day were assigned for study. The test group was fed $500 \mathrm{mg} / \mathrm{kg}$ hydroalcoholic extract orally from 8 th day to $37^{\text {th }}$ day.

\section{Statistical analysis}

The Data were analyzed by One-way analysis of variance (ANOVA) and Values were considered at $\mathrm{p}<0.05$.

\section{Parameter evaluated}

- Blood glucose

- Glycosylated Hemoglobin

- Lipid Profile

- Serum creatinine

- SGPT

- Histopathology of liver

- Histopathology of kidney.

\section{RESULTS}

\section{Effect of M. koenigii leaves extract on blood glucose and glycosylated hemoglobin}

Blood Glucose level in STZ Control Group (Diabetic Control) was significantly high on $22^{\text {nd }}$ and $37^{\text {th }}$ day as compare with Sham Group (Health Control).

In Murraya koenigii treated group the Blood glucose concentration was significantly reduced as compare with Control group.

The Murraya koenigii also significantly reduced the Glycosylated Hemoglobin in treated group as compare with Control group. These results confirms the hypoglycemic effect of Murraya koenigii. (Figure 1 and 2).

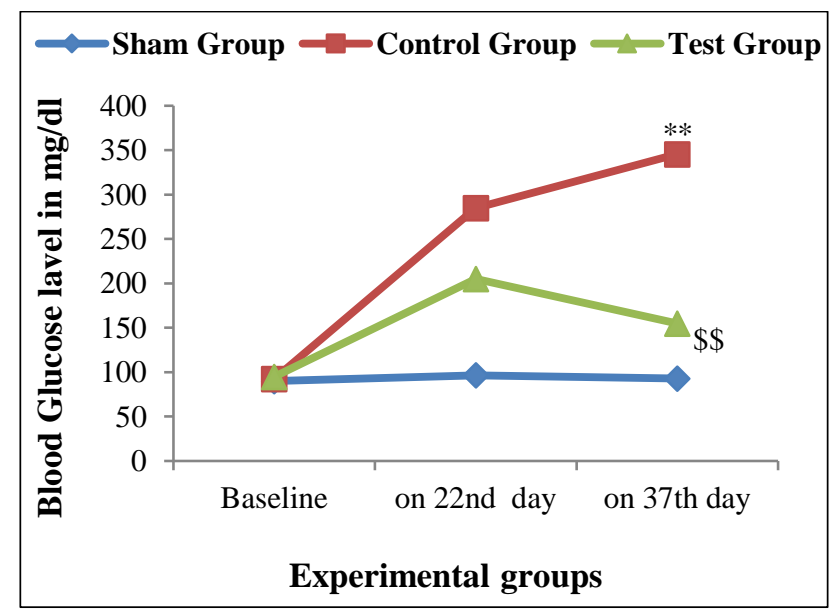

$* * \mathrm{p}<0.01$ sham vs Control gp, $\$ \$ p<0.01$ Control vs Test grp

Figure 1: Time point Changes in Blood Glucose Level.

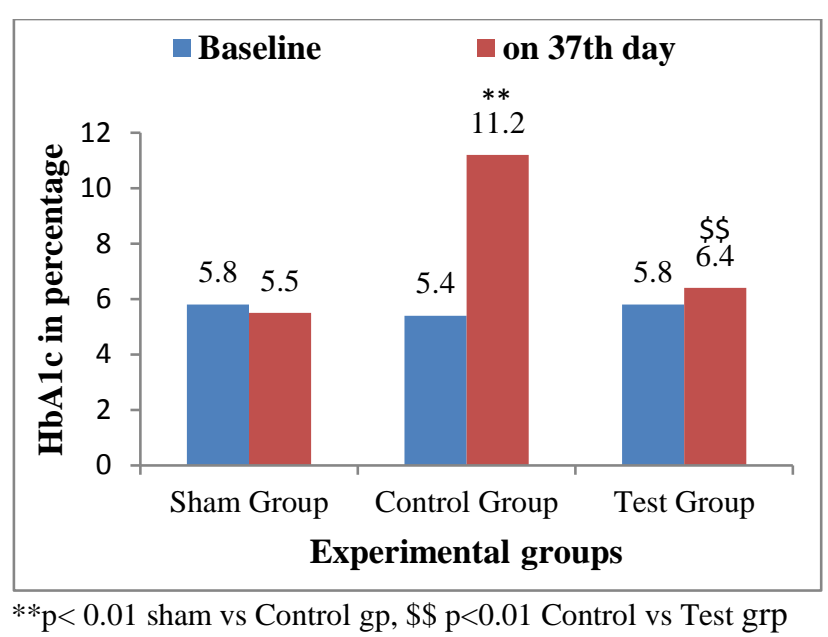

Figure 2: HbA1c Level among experimental groups.

Effect of Murraya koenigii extract on plasma Lipid profile.

The Murraya koenigii treatment also showed the antihyperlipidemic activity as it reduced the triglyceride level significantly in treated group as compare with Control group on 37th day. In other hand High density lipoprotein (HDL) Cholesterol was marked increased in treated group than control group. (Figure 3). The treatment by Murraya koenigii is safe to pancreas, Liver and Kidney as reported by biochemical finding and histopathological report. (Table 1, Figure 4).

\section{Histopathological assessments}

Plate 1: A: Photomicrograph of Liver sections of Sham group rats shows, normal architecture live. B: The liver of Control group rat shows inflammatory infiltration more and congestion of blood vessels in central vein. C: Test group rats liver shows, less congestion of blood vessels less inflammatory infiltration and normal structure of central vein, peripheral vein (Figure 4a).

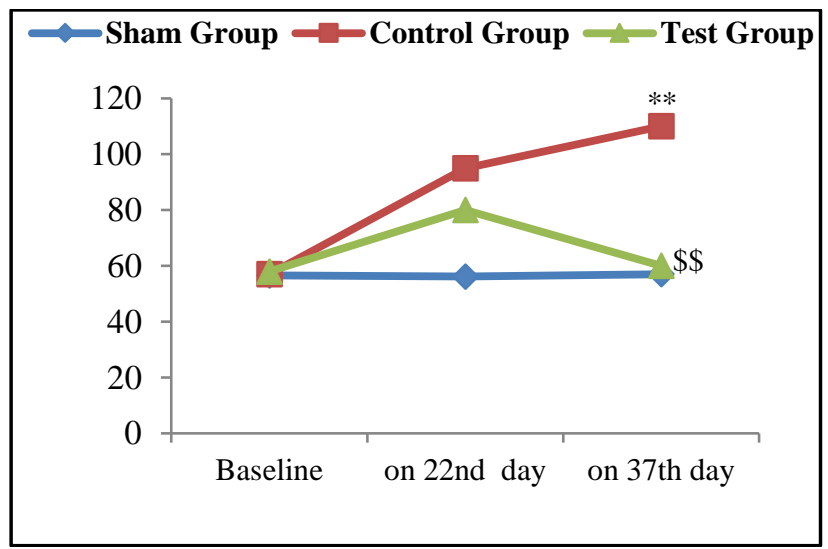

$* * \mathrm{p}<0.01$ sham vs Control gp, $\$ \$ p<0.01$ Control vs Test grp

Figure 3: Triglyceride level among various experimental groups. 
Table 1: Safety marker in various experimental groups.

\begin{tabular}{|llll|l|}
\hline Sr. No. & Variable & Sham group & Control group & Test group \\
\hline 1 & Pancreatic Marker Pancreatic Lipase(U/L) & $30.66 \pm 2.10$ & $48.26 \pm 9.36$ & $36.83 \pm 1.50^{*}$ \\
\hline 2 & Liver Marker SGPT(U/L) & $61.25 \pm 8.68$ & $99.85 \pm 10.38$ & $77.42 \pm 7.20^{* *}$ \\
\hline 3 & Kidney Marker Creatinine $(\mathrm{mg} / \mathrm{dl})$ & $0.32 \pm 0.07$ & $1.27 \pm 0.43$ & $0.51 \pm 0.06 *$ \\
\hline
\end{tabular}

Values are expressed as Mean \pm SD. ${ }^{*} p<0.05^{* *} \mathrm{p}<0.01$ Control Vs Test group.

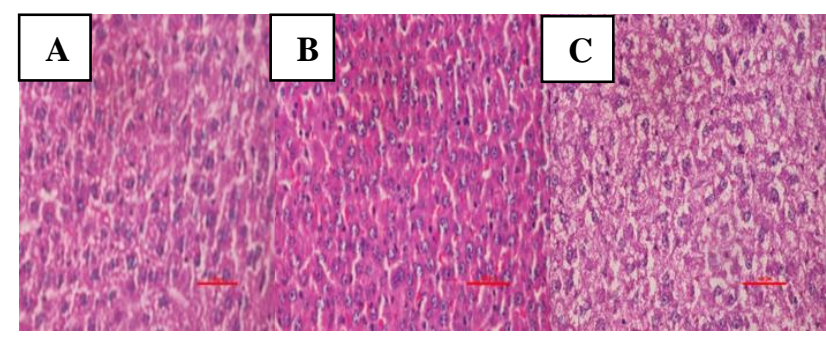

Figure 4(a): Histopathological assessments of liver tissue sections stained with $H$ and $E$. (A): Sham group-Normal architecture of central vein and hepatocytes, (B): Control group-More inflammatory infiltration and congestion of blood, $(C)$ : Test groupLess congestion of blood vessels and less inflammatory infiltration as compared to Control group; Scale bar $=100 \mu \mathrm{m}$

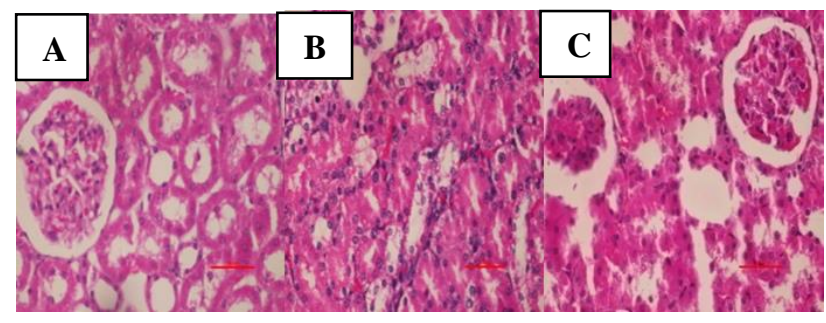

Figure 4(b): Histopathological assessments of liver tissue sections stained with $H$ and E. (A): Sham group: Normal structure of the kidney, (B): Control group-Marked congestion of glomerular blood vessels, tubular necrosis, inflammation, $(C)$ : Test group-No congestion of glomerular blood vessels, less inflammation ; Scale bar $=100 \mu \mathrm{m}$

Plate 2: A: Photomicrograph of Kidney sections of Sham group rats shows normal structure of the kidney. B:Control group rat demonstrated congestion of glomerular blood vessels, tubular necrosis, inflammation and cloudy degeneration. C: Test group kidney shows, no congestion of glomerular blood vessels, less tubular necrosis, inflammation (Figure 4b).

\section{DISCUSSION}

Murraya koenigii leaves is found to have alanine, lysine, carbohydrates, iron, calcium, niacin and volatile oils. Aqueous and methanol extracts of Murraya koenigii treatment for eight weeks has caused significant increase in the insulin concentration in diabetic $\mathrm{T} 1$ and $\mathrm{T} 2$ groups respectively. The increased insulin secretion in diabetic T1 and diabetic $\mathrm{T} 2$ groups could be due to presence of alanine, leucine, carbohydrate, niacin, iron. ${ }^{1}$ The increase in plasma insulin concentration could also be due to the longer lasting stimulant effect on $\beta$-cells of pancreatic islets or due to pancreatic $\beta$-cells regeneration of Murraya koenigii. ${ }^{9}$

Streptozotocin is a $\beta$-cytotoxin, induces, chemical diabetes, in a wide variety of animal species including rat by selectively damaging the insulin-secreting $\beta$-cells of the pancreas.

The purpose of choosing Streptozotocin as diabetesinducing agent was known to produce diabetes mellitus irreversibly with a single dose of intraperitoneal administration by relative necrotic action on the $\beta$-cells of pancreas leading to insulin deficiency. ${ }^{10}$

The present study showed a Hypoglycemic effect of test drug by significantly decreasing the Blood glucose and Glycosylated Hemoglobin in diabetic rats treated with Murraya koenigii leaves extract ( $500 \mathrm{mg} / \mathrm{kg}$ body weight) compared to that of untreated diabetic rats. The similar study conducted by Venuthanet al, (2004) using Murraya koenigii (200-600 mg/kg) showed that the Murraya koenigii extract lowers the Blood Glucose level, however they have not assessed Glycosylated Hemoglobin level. The study by Dineshkumar et al, possess similar results as compare with present study. ${ }^{1,8}$

Mitraa E et al, and Ghosh D et al, indicated that the aqueous extract of Curry leaf protects the rat cardiac tissue against cadmium-induced oxidative stress possibly through its antioxidant activity. ${ }^{11,12}$ The study also showed reduced level of lipid profile, similar reported by present study. The present study documented that reduced triglyceride level and increase the HDL level. All these changes were ameliorated when the rats were pre-treated with an aqueous extract of Curry leaf.

\section{CONCLUSION}

The present study concluded that, the Murraya koenigii extract exhibit the antidiabetic activity and it also showed marked Hypolipidemic, effect in presence of diabetes.

Funding: No funding sources Conflict of interest: None declared

Ethical approval: The study was approved by the Institutional Ethics Committee 


\section{REFERENCES}

1. Vinuthan MK, Girish Kumar V, Ravindra JP, Narayana K. Effect of extracts of Murraya koenigii leaves on the levels of blood glucose and plasma insulin in alloxan-induced diabetic rats. Ind J Physiol Pharmacol. 2004;48(3):348-52.

2. Aiman R. Recent research in indigenous antidiabetic medicinal plants: An overall assessment. Indian J Physiol Pharmacol. 1970;14(2):65-76.

3. Wild S, Roglic G, Green A, Sicree R, King H. Global prevalence of diabetes: estimates for the year 2000 and projections for 2030. Diabetes care. 2004;27(5):104753.

4. Bonde SD, Nemade LS, Patel MR, Patel AA. Murraya koenigii (Curry leaf): Ethnobotany, phytochemistry and pharmacology-A review. Int $\mathrm{J}$ Pharmaceut Phytopharmacol Res. 2011;1(1):23-7.

5. Xie JT, Chang WT, Wang CZ, Mehendale SR, Li J, Ambihaipahar R. Am J Chin Med. 2006;34(22):27984.

6. Shrinivasan, K. Plant foods in the management of diabetes mellitus: spices as beneficial antidiabetic food adjuncts. Int J Food Sci Nutr. 2005;56(6):399414.

7. Kesari AN, Gupta RK, Watal G. Hypoglycemic effects of Murraya koenigii on normal and alloxandiabetic rabbits. J Ethnopharmacol. 2005;97(2):24751.
8. Dineshkumar B, Mitra A, Mahadevappa M. Antidiabetic and hypolipidemic effects of mahanimbine (carbazole alkaloid) from Murraya koenigii (rutaceae) leaves. Int J Phytomed. 2010;2(1).

9. Bhat SS. The antidiabetic activity of Murraya koenigii Spreng and the hyperglycemic activity of Leucas aspera spreng. MV Sc (Doctoral dissertation, thesis submitted to UAS, Bangalore, India).

10. Kumar NJ, Loganathan P. Hypoglycemic effect of Spinacia oleracea in alloxan induced diabetic rat. Glob J Biotechnol Biochem. 2010;5:87-91.

11. Mitra E, Ghosh AK, Ghosh D, Mukherjee D, Chattopadhyay A, Dutta S, et.al, Protective effect of aqueous Curry leaf (Murraya koenigii) extract against cadmium-induced oxidative stress in rat heart. Food Chem Toxicol. 2012;50(5):1340-53.

12. Ghosh D, Syed BF, Mitra E, Chattopadhy A, Pattari SK, Dutta S, et al. Aqous leaf extract of murryakoengii protects against lead-induced cardio-toxicity in male wistar rats. Int J Phytopharmacol. 2013;4(2):119-133.

Cite this article as: Suman RK, Ray I, Borde MK, Deshmukh YA, Pathak A, Adhikari AK, et al. Evaluation of antidiabetic efficacy of Murraya koenigii on Streptozotocin induced diabetes in experimental rats. Int J Basic Clin Pharmacol 2019;8:1906-10. 